\title{
Derecho a la Salud y Seguridad Alimentaria frente a los alimentos con contenido transgénico
}

Right to Health and Food Safety over foods with transgenic content

\author{
Martha Lucia Cullquicondor-Soliz \\ martha.cullquicondor@psg.ucacue.edu.ec \\ Universidad Católica de Cuenca, Cuenca \\ Ecuador \\ https://orcid.org/0000-0002-4613-1175 \\ Juan Carlos Erazo-Álvarez \\ jcerazo@ucacue.edu.ec \\ Universidad Católica de Cuenca, Cuenca \\ Ecuador \\ https://orcid.org/0000-0001-6480-2270 \\ Cecilia Ivonne Narváez-Zurita \\ inarvaez@ucacue.edu.ec \\ Universidad Católica de Cuenca, Cuenca \\ Ecuador \\ https://orcid.org/0000-0002-7437-9880 \\ Enrique Eugenio Pozo-Cabrera \\ epozo@ucacue.edu.ec \\ Universidad Católica de Cuenca, Cuenca \\ Ecuador \\ https://orcid.org/0000-0003-4980-6403
}

Recibido: 11 de abril de 2020 Revisado: 25 de abril de 2020 Aprobado: 31 de mayo de 2020 Publicado: 17 de junio de 2020 


\title{
RESUMEN
}

La seguridad alimentaria es uno de los temas que más preocupa a la sociedad, pues se considera que existen organismos invisibles adecuados a los productos, dejando en la incertidumbre su compuesto, a esta realidad se suma la investigación del presente trabajo, que tiene a bien resumir de manera explícita, lo que son los alimentos transgénicos desde el punto de vista teórico, comenzando por una definición clara e inviolable como es el derecho a la Salud y a la Soberanía Alimentaria, que garantizan el buen vivir de los seres humanos, sin duda no caben distributivos contrarios, ya que resulta claro que el Estado garantiza el derecho al acceso seguro y permanente a alimentos sanos conforme así lo establece la Constitución, sucede pues, que, los organismos modificados genéticamente o más conocidos como alimentos transgénicos, son productos que a diario sobrellevan una transformación en los genes afligiendo la Salud de la población.

Descriptores: Organismo modificado genéticamente; política de la salud; seguridad alimenticia; diversidad biológica; genética agrícola. (Palabras tomadas del Tesauro UNESCO).

\begin{abstract}
Food security is one of the subjects that most worries society, since it is considered that there are invisible organisms suitable for products, leaving their compound in uncertainty, to this reality the research of this work is added, which is apt to summarize explicitly, what are genetically modified foods from a theoretical point of view, starting with a clear and inviolable definition such as the right to Health and Food Sovereignty, which guarantee the good living of human beings, certainly do not fit contrary distributive, since it is clear that the State guarantees the right to safe and permanent access to healthy food as established by the Constitution, it happens, then, that genetically modified organisms or better known as transgenic foods, are products that daily cope a transformation in genes afflicting the health of the population.
\end{abstract}

Descriptors: Genetically modified organisms, health policy, food safety, biological diversity, agricultural genetics. (Words taken from the UNESCO Thesaurus)

\section{INTRODUCCIÓN}

En el Ecuador y el mundo conoce que los alimentos transgénicos, son productos que han sido transformados de su estado natural a otro estado, esto se manifiesta con el fin de perseverar la salud de la población humana, pero con ello se ha vulnerado los derechos de las personas, la salud alimentaria y la especie humana, en efecto se 
puede decir que no representa un problema solo para nuestro país, sino también a nivel de Latinoamérica y el mundo, puesto que las grandes empresas biogenéticas tiene objetivos contrarios al principio del Buen Vivir y la soberanía alimentaria.

Si bien es cierto lo que parece que es un efecto natural de este fenómeno transgénico, los habitantes de muchas zonas a nivel latinoamericano, no están dispuestos a dejarse influenciar por la globalización, el productivismo y a facilitar la expansión del agro genética. Segrelles (2013) por el contrario afirma que "se han organizado para llevar a cabo diversas formas de agricultura sostenible basadas en el desarrollo de los cultivos orgánicos y en la recuperación de su inmensa riqueza genética" (p.19).

Aunque la siembra transgénica está prohibida, lo cierto es que la venta del producto ya está listo para el consumo y no tiene limitación, sino por el contrario en los supermercados del país se pueden encontrar diversas marcas de estos productos, siendo el semáforo del etiquetado el cual advierte que el consumidor está adquiriendo este tipo de alimento, en resumidas cuentas se puede decir que afecta a la salud humana y a la seguridad jurídica, la producción, venta y distribución de alimentos con contenido transgénico, existiendo la posibilidad de que se desarrollen enfermedades en el ser humano.

Es por ello, que es conveniente realizar una investigación profunda que permitirá analizar y determinar la importancia de lo que es la salud humana y de este modo garantizar la alimentación a través de la ingesta de productos que no hayan sido alterados químicamente. El art. 15. Menciona que "se prohíbe...agentes biológicos experimentales nocivos y organismos genéticamente modificados perjudiciales para la salud humana o que atenten contra la soberanía alimentaria o los ecosistemas..." (Asamblea Constituyente, 2008).

Por esto, analizando los grandes problemas y beneficios que han traído los alimentos con contenido transgénico para la humanidad, este tipo de alimentos han sido objeto de estudio y polémica, ya que existen posiciones enfrentadas entre los que están de acuerdo y aquellos expertos que están en contra de su utilización, resulta claro que la investigación aportará con la revisión bibliográfica de teoría correspondiente a lo que es la Seguridad alimentaria, alimentos transgénicos y salud humana. 
En la perspectiva que aquí adaptamos se plantea como problema ¿Cómo evitar la vulneración de los Derechos Constitucionales a la salud y a la soberanía alimentaria por la producción, venta y distribución de alimentos con contenido transgénico? En relación a la problemática expuesta el objetivo es proponer un protocolo de seguimiento, análisis y cumplimiento del derecho la salud frente a los organismos modificados genéticamente.

\section{Referencial teórico}

\section{La vulneración de derechos constitucionales a la salud, por la producción venta y distribución de transgénicos.}

Los Derechos Humanos son inherentes a la persona, irrevocables, inalienables, intransmisibles e irrenunciables, es un derecho universal, se conoce que los alimentos transgénicos son productos que cada día sufren una transformación en sus genes, producen por la existencia de químicos, para promover los efectos ansiados, por parte de las grandes empresas biogenéticas del país, perdiendo así su estado natural por químico.

Un alimento orgánico (o ecológico) se caracteriza por ser sano, seguro y sabroso. Según Brandt, Leifert, Sanderson y Seaj citados por (Gómez, 2012) "las frutas y verduras cultivadas sin abono sintético y sin pesticidas registraban un mayor contenido de vitamina $\mathrm{C}$, sin por ello arrojar grandes diferencias con los productos convencionales. Siendo el producto ecológico sabroso y aromático, un alimento ecológico puede ser la base estratégica de nuestra gastronomía, considerada ya como una de las mejores del mundo".

De tal forma que el producto ecológicamente producido tiene muchas ventajas a considerar sobre lo que es el producto transgénico, por lo que, un organismo genéticamente modificado o transgénico (OGM) también se puede definir como "un organismo cuyo material genético ha sido modificado de una manera que no se produce naturalmente en el apareamiento ni en la recombinación natural" (Rodríguez, 2013)

Con respecto a las razones por las cuales se considera que los productos transgénicos no son recomendables para el consumo humano, pero los que defienden esta nueva 
tecnología, incluso llegan a expresar las ventajas que representa su aplicación para el agricultor:

i. Menores costos de producción al requerir un menor empleo de agroquímicos, tanto para los cultivos tolerantes a herbicidas como para los resistentes a insectos, hongos y enfermedades.

ii. Mayores rendimientos potenciales por hectárea respecto a las variedades "no-OGM", mas no por la semilla en sí, sino porque se reducen las pérdidas ocasionadas por la acción de insectos y se incrementa la capacidad de los cultivos para competir con las malezas;

iii. Mejora el manejo de los cultivos, al simplificar el uso de herbicidas y pesticidas, ya que se reducen o eliminan la cantidad de aplicaciones y disminuyen las tareas de detección de plagas;

iv. Por el momento, no varían los ingresos absolutos por ventas en relación a las semillas convencionales, pues como los productos son iguales, los precios que se obtienen por la producción son los mismos. No obstante, ello, esto puede modificarse en dos casos. El primero es que tengan mayor precio las variedades que difieren en su calidad y/o en las prestaciones que brindan al consumidor, como ser mayor tiempo de conservación en condiciones aptas, mejoras en el gusto, ventajas para el procesamiento industrial y rasgos nutricionales y médicos -v.g., prevención de enfermedades-. Por el contrario, en el caso de los transgénicos de primera generación el impacto sería negativo, ya que si se tornara difícil la colocación de estos productos -debido a la resistencia de los consumidores a adquirirlos-, caería el volumen de las ventas o, si se intentara mantener la cantidad comercializada, se tendría que reducir el precio de venta" (Galperín, Fernández, \& Doporto, 2013).

Visto de esta forma se trata de establecer en forma clara y concreta el problema de la investigación de los alimentos transgénicos, dentro de la normativa jurídica constitucional que garantiza y protege a la raza humana, en donde se puede ver que el Estado evidencia una serie de crisis en estos aspectos, dentro de la cual existe una legislación constitucional que protege a la vida humana y eso se pretende incorporar 
en este tema mediante una amplia bibliografía de muchos juristas, abogados, tratadistas, de nuestro ordenamiento jurídico, del derecho comparado y personas conocedoras del problema en cuestión (Abad Romero, Erazo Álvarez, Ormaza Ávila, \& Narváez Zurita, 2020).

Cabe considerar, por otra parte, que esta propuesta es dar a conocer los pro y los contras de los alimentos transgénicos, Dentro de este marco la Constitución de la República del Ecuador es totalmente clara cuando prohíbe la producción y siembra de productos con alteraciones químicas que hagan posible mejorar sus características, puesto que, no hay ningún documento científicamente comprobado que afirme que no existe ningún tipo de perjuicio a la salud humana, aunque tampoco hay alguno que afirme lo contrario.

\section{La salud es un derecho fundamental de todo ser humano.}

La organización Mundial de la Salud (OMS) señala sobre la responsabilidad que tienen los gobiernos para que todas las personas tengan derecho a la salud. Que el goce del grado máximo de salud que puede lograr es uno de los derechos fundamentales de todo ser humano (Organización Mundial de la Salud, 2016). El compromiso de los gobernantes es el de velar por la salud y bienestar de cada uno de sus habitantes, siguiendo un debido protocolo salubridad.

El Art. 358.- El sistema nacional de salud tendrá por finalidad el desarrollo, protección y recuperación de las capacidades y potencialidades para una vida saludable e integral (Asamblea Constituyente, 2008). En este sentido se comprende que la salud es un derecho fundamental para todas las personas pues es un derecho vital, se refiere a tener una atención médica cuando se necesita y además tener todas las precauciones sanitarias para prevenir enfermedades.

Es por ello que la salud es un derecho que garantiza el Estado, cuya realización se vincula al ejercicio de otros derechos, entre ellos el derecho al agua, la alimentación, la educación, la cultura física, el trabajo, la seguridad social, los ambientes sanos y otros que sustentan el buen vivir. (Asamblea Constituyente, 2008, art. 32)

Hay que tener en cuenta que el Ecuador es un país rico en productos agrícolas naturales, y que es una de las fuentes de trabajo y producción interna de los Ecuatorianos, en base a lo expuesto se plantea los conceptos y definiciones 
principales sobre la temática presentada, de tal forma que se conoce lo que son los alimentos, los alimentos transgénicos, lo que dice la Constitución de la República del Ecuador (CRE) aprobada en el año 2008 y su prohibición clara y concreta sobre la producción de estos alimentos en el país, aunque no hace referencia a la venta (BravoNúñez, Narváez-Zurita, Vázquez-Calle, \& Erazo-Álvarez, 2020).

A nivel mundial, la producción alimenticia se ve afectada de acuerdo a las zonas geográficas, ya que es en África en donde es evidente la inexistencia de condiciones adecuadas para permitir cultivos tradicionales que, a su vez, contribuyan a disminuir los problemas de alimentación y hambre que actualmente existen. La pobreza de estos pueblos hace imposible que los pocos cultivos existentes lleguen a satisfacer las necesidades alimenticias de esos pobladores, a ello hay que considerar que no disponen de control de plagas y enfermedades sobre el cultivo, y que en muchos casos lleva a la pérdida completa de la cosecha tan esperada. (Ramírez, 2013, p. 71) Tomando como bandera el brindar la solución a este problema acuciante de la alimentación en países subdesarrollados, algunas corporaciones se han dedicado a desarrollar tecnología agrícola para mejorar el producto, alterando sus características para hacerla más durable, más resistente a plagas y con rapidez de crecimiento.

El aumento del uso de diversas tecnologías, y químicos, así como nuevas variedades de cultivos de alto rendimiento se emplearon en las décadas después de la Segunda Guerra Mundial. (Romero, 2012), para aumentar en gran medida la producción alimentaria mundial. El art. 13.- menciona que las personas y colectividades tienen derecho al acceso seguro y permanente a alimentos sanos, suficientes y nutritivos; preferentemente producidos a nivel local y en correspondencia con sus diversas identidades y tradiciones culturales. El Estado ecuatoriano promoverá la soberanía alimentaria. (Asamblea Constituyente, 2008)

\section{Los alimentos con contenido transgénicos son nocivos y perjudiciales para la salud.}

Se define alimentos con contenido transgénico, aquellos que han tenido algún tipo de modificación genética dejando a un lado lo natural para convertirse en un alimento con químico, insertando nuevas proteínas en sus genes, dando como resultado un producto ajeno a la naturaleza, por lo que son poco recomendables para la salud de 
los seres humanos, peor aún para su consumo, ya que se considerar perjudiciales para la salud, inclusive puede presentar reacciones poco favorables en los humanos. Si el conjunto de técnicas transgénicas se encaja, debe hacerlo considerando la aportación de agricultores, ganaderos y consumidores, y no depender de patrocinios políticos y fructíferos de macroempresas (Manrique \& Verduzco, 2011). Motivo por el cual se mantienen obligaciones económicas a largo plazo y conflictos ecológicos diversos que deben examinarse, teniendo en cuenta los principios de precaución y responsabilidad hacia futuras generaciones, en conclusión, se puede argumentar la importancia de la salud humana y garantizar lo que es la alimentación a través de la ingesta de productos que no hayan sido alterados químicamente, vulnerando así los derechos Constitucionales a la salud y a la soberanía alimentaria.

El candado constitucionalmente impuesto permite garantizar la pureza de los productos alimenticios, evitando los sembríos transgénicos sobre todo de maíz. En el Ecuador que es un país cuyos campos han sido apropiados para la producción agrícola, sobre todo de variedades de granos de maíz, aunque hay algunas que ya no se siembran debido sobre todo a los problemas económicos de la importación de granos de Colombia o Perú, que hacen competencia al producto nacional (León, 2013, p. 29,53$)$.

En la valoración del impacto ambiental de los organismos modificados genéticamente los sucesos son más difusos, por la ausencia o desconocimiento de técnicas para examinar las inseguridades medioambientales (Ramón, 2014). Teniendo en cuenta que cientos de plantas transgénicas tienen un proceso denominado liberación controlada al ambiente y es inevitable acarrear en diferentes ecosistemas.

Aunque la siembra transgénica está prohibida, lo cierto es que la venta del producto ya listo para el consumo no tiene esta limitación, sino que por el contrario en los supermercados del país se pueden encontrar diversas marcas de estos productos, siendo el semáforo del etiquetado el cual advierte que el consumidor está adquiriendo este tipo de alimento. Los alimentos se pueden definir como:

Todo producto natural o artificial, elaborado o no, que ingerido aporta al organismo humano los nutrientes y la energía necesaria para el desarrollo de los procesos biológicos. Quedan incluidas en la presente definición las bebidas no alcohólicas y aquellas sustancias con que se sazonan algunos 
comestibles, conocidas con el nombre genérico de especia". (Almendrales,

Cante, Riaño, Moreno, \& Duarte, 2012)

El consumo de alimentos está determinado por costumbres culturales, hábitos alimentarios, influencia de la información comercial y niveles educativos. La importancia de los alimentos radica en que con ellos se garantiza la satisfacción de las necesidades humanas de nutrición. Por lo tanto, la alimentación es un derecho que no solo está vigente en la legislación interna, sino a nivel internacional la nutrición del ser humano es una prioridad de organismos como la FAO, que lucha de forma constante para garantizar esas necesidades alimentarias en países cuyas economías no permiten que sus ciudadanos lleven una vida digna y saludable.

Con respecto a los efectos que sobre la salud pueden tener o llegar a tener el consumo de alimentos transgénicos, hay que considerar no sólo la salud sino también el riesgo en cuanto a la seguridad alimentaria que puede darse por la contaminación transgénica, ya que en estos cultivos el uso del fertilizante, pesticidas, plaguicidas $u$ otros químicos, puede aumentar la vulnerabilidad de la salud humana.

En opinión de Seralini "los mecanismos de evaluación de riesgos previos a la liberación de un transgénico no están diseñados para proteger ni la salud, ni el medio ambiente" (Ramírez, 2013)

\section{Derecho de las personas a la Soberanía Alimentaria.}

En el año 2001 el Foro Mundial de Soberanía Alimentaria estableció que:

La Soberanía Alimentaria es el derecho de los pueblos a definir sus propias políticas y estrategias sustentables de producción, distribución y consumo de alimentos que garanticen el derecho a la alimentación para toda la población, con base en la pequeña y mediana producción, respetando sus propias culturas y la diversidad de los modos campesinos, pesqueros e indígenas de producción agropecuaria, de comercialización y de gestión de los espacios rurales, en los cuales la mujer desempeña un papel fundamental. (La Vía Campesina, 2015).

La soberanía alimentaria es un concepto que fue introducido con mayor relevancia en 1996 por Vía Campesina en Roma, con motivo de la Cumbre Mundial de la Alimentación de la Organización para la Alimentación y la Agricultura (FAO) (Waldmueller \& Rodriguez, 2015). En torno a la cual no se ha desarrollado un régimen 
no vinculante sobre la agricultura, la produccion y el consumo de alimentos transgénicos.

El concepto de seguridad alimentaria ha sido utilizado con diferentes sentidos a lo largo del tiempo. A partir de la Conferencia de Alimentación celebrada en Roma en 1974 han surgido diversas definiciones lo que no le resta importancia al tema, sino por el contrario los múltiples usos del término reflejan la naturaleza del problema alimentario. En la seguridad alimentaria históricamente se pueden definir tres grandes momentos que quizás no han sido tan explícitos. Los tres cambios son:

a) De un enfoque global y nacional al de la seguridad alimentaria familiar e individual,

b) De una primera perspectiva centrada en el alimento hacia una perspectiva sobre la seguridad de los medios de vida y

c) De indicadores de objetivos a indicadores de percepción.

El riesgo que en la actualidad se cierne sobre la soberanía alimentaria reconocida constitucionalmente en el país es que se estaría considerando desde el Estado y del Ministerio de Agricultura apertura la utilización de químicos transgénicos en los sembríos ecuatorianos. "Es especialmente preocupante que en muchos de los aspectos relacionados con el impulso a la agricultura se promueva el cultivo de alrededor de 50.000 hectáreas de soya y 20.000 has de canola probablemente del mismo origen transgénico" (Acción Ecológica, 2013).

Las empresas multinacionales tratan de controlar la alimentación mundial, creando un gran oligopolio mundial, obteniendo grandes beneficios a costa de los agricultores, consumidores y pequeños comerciantes (Chumbi-Pulla, Erazo-Álvarez, TrellesVicuña, \& Narváez-Zurita, 2020).

En la actualidad se recuerda que desde hace décadas atrás existían plantas resistentes a la agresión de plagas, sin que hayan tenido un debido proceso de desinfección. Por su referencia se les conoce con el nombre de primera generación de transgénicos y cubren casi la totalidad de los que ahora se comercializan. Han sido los primeros en desarrollarse porque dependen de un único gen y, por lo tanto, su generación es relativa-mente sencilla y también porque se trata de desarrollos con indudable interés comercial para los agricultores, lo que asegura su venta. (Ramón, 
2014, p. 90). La Constitución ecuatoriana recoge, por lo tanto, las condiciones del Buen Vivir se encuentran fundamentadas en el artículo 275 (Asamblea Constituyente, 2008).

\section{MÉTODO}

Adoptando los diversos pensamientos e ideologías adquiridas mediante encuesta en concordancia con el tema avanzado, se deja sentado que la metodología se apoyó en el temperamento de índole no empírico, teniendo en cuenta que se estudió información fiable de todos los datos proporcionados y relacionados con el tema dando una perspectiva compuesta como lo es el inductivo, deductivo, analítico y el sintético, recalcando y respetando cada criterio con la aspiración de atraer la atención de los lectores.

El método Analítico-Sintético es el enfoque de esta investigación misma que observa todos los pensamientos y observaciones de la información recopilada de manera desmenuzada de los encuestadores, debidamente transcrita y representada mediante gráficos de fácil interpretación, con la finalidad de dar una recapitulación global del fenómeno estudiado.

En relación a la problemática expuesta queda sentado que también se usó la metodología Inductiva-Deductiva, puesto que, comprende una problemática particular como es el alimento transgénico frente a la salud de los seres humanos, para expresar un criterio general al resto de ciudades dentro del país, y así llegar a conocer su punto de vista en relación al tema mencionado. (Rodríguez, 2005) afirma. "El método Inductivo que se procesó en el que, a partir del estudio de casos particulares, se obtienen conclusiones o leyes universales que explican o relacionan los fenómenos estudiados" (p.89). Tomando en consideración que el Estado ecuatoriano garantiza el derecho a la salud de sus habitantes.

Análisis documental jurídico, en relación a la ponderación de derechos, siendo estos el análisis entre el derecho a la vida y el derecho al trabajo, acotando el criterio personal e individual de los encuestados.

A título ilustrativo se denota que las encuestas se realizaron a Jueces Constitucionales de la Ciudad de Cuenca, a varios abogados en libre ejercicio de la profesión, y a 
Médicos generales, de esta manera conocer su punto de vista, su criterio profesional y a su vez plantear una solución aplicable al tema materia de investigación sin vulnerar los derechos constitucionales protegiendo a su vez, la salud, la alimentación sana y porque no decir el derecho al trabajo, respetando el debido proceso.

\section{Universo de estudio y tratamiento muestral}

Dentro de este marco se utilizó el muestreo por vigor que es una pericia de índole no probabilístico y aleatorio, que está formado por análisis y criterios facilitados por varias personas profesionales en esta rama, resumiendo así: 7 Jueces Constitucionales, 10 abogados en libre ejercicio de la profesión y 3 médicos generales.

\section{Tratamiento estadístico de la información}

Los datos obtenidos fueron a través de cuestionarios mediante los formularios realizados por Google (https://docs.google.com/forms), estos fueron procesados en tablas de datos que compilan las respuestas de las personas involucradas en la investigación, y se tabulan los resultados más importantes en el programa Microsoft Excel versión 2019 (Calle, Narváez, \& Erazo, 2019).

\section{RESULTADOS}

A continuación, se presenta la Tabla y la Figura 1 con el resumen de los resultados obtenidos, clasificados según las variables definidas en el instrumento de investigación aplicado: 


\section{Tabla 1}

Variables

\begin{tabular}{|c|c|c|}
\hline \multirow[b]{2}{*}{ Variable } & \multicolumn{2}{|c|}{ Resultado \% } \\
\hline & Si & No \\
\hline Derecho alimentos sanos & $30,00 \%$ & $70,00 \%$ \\
\hline Derechos Humanos & $60,00 \%$ & $40,00 \%$ \\
\hline \multicolumn{3}{|c|}{ Garantizar la realización del Buen } \\
\hline Vivir & $60,00 \%$ & $40,00 \%$ \\
\hline Soberanía Alimentaria & $70,00 \%$ & $30,00 \%$ \\
\hline Derecho al trabajo & $30,00 \%$ & $70,00 \%$ \\
\hline Principio del Buen Vivir & $65,00 \%$ & $35,00 \%$ \\
\hline Responsabilidad del Estado & $40,00 \%$ & $60,00 \%$ \\
\hline
\end{tabular}

Fuente: Investigación de campo

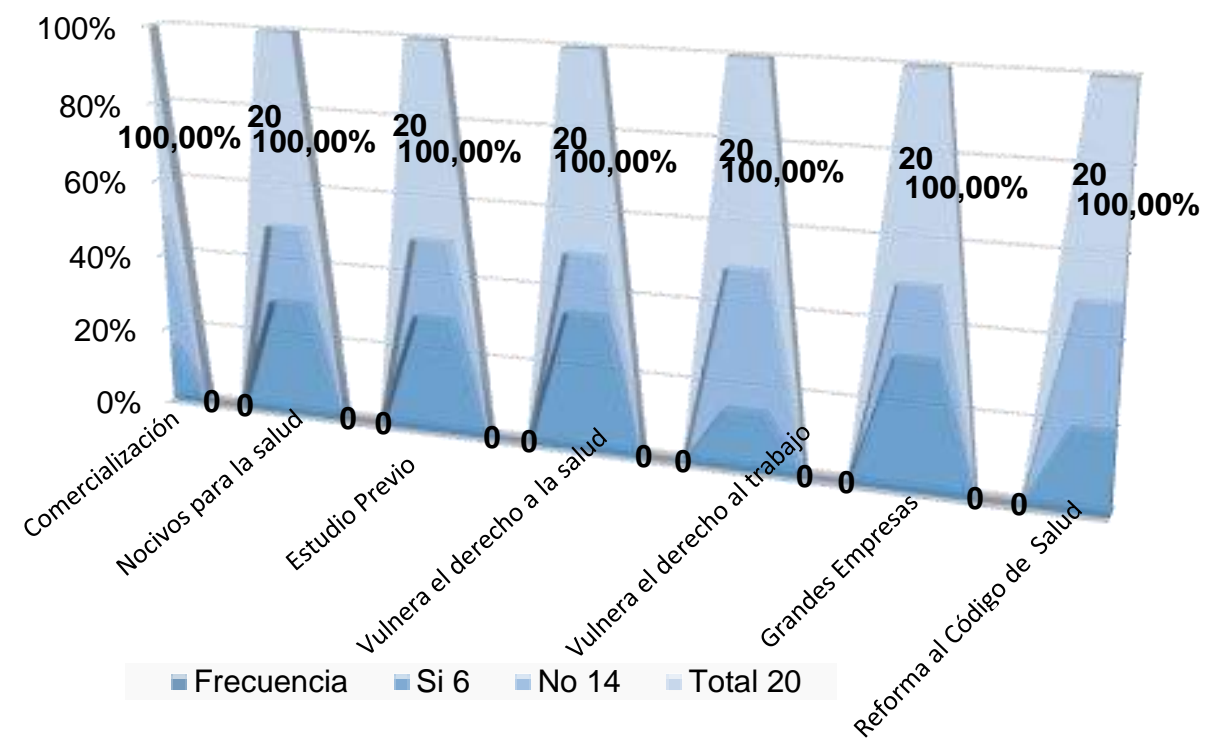

Figura 1. Variables. Fuente: Investigación de campo. 
De los resultados obtenidos se puede denotar que los transgénicos son alimentos alterados químicamente, que en ciertos casos contaminan el medio ambiente, causando daños no solo en las personas, sino también en plantas y animales, caracterizándose nocivos para la salud, ya que son resistentes a plagas, las que en ciertos casos causan alergias leves en las personas, por lo que consideran no factibles para la comercialización, venta y producción, sin embargo hay quienes tiene un criterio diferente y manifiestan que se deberían hacer estudios previos para garantizar la calidad del producto y por ende su consumo a fin de permitir su expansión en el mercado.

Tenemos pues, que considerar que queda la incertidumbre respecto a la manipulación genética de los mismos, ya que puede traer consecuencias a futuro, precisemos, antes que nada, que dentro de la variable de la Soberanía Alimentaria, existe un gran porcentaje que considera que se vulnera el derecho a la salud al permitirse su distribución y no se estaría garantizando alimentos sanos, puesto que los alimentos deben ser suculentos en proteínas y en calcio de fácil asimilación, ya que los dos nutrientes son substanciales para el crecimiento y desarrollo del ser humano (Bello, 2015).

Los seres vivos compartimos tanta información y nos somos tan diferentes, desde el punto de vista genético, ¿no debería ser esto un elemento para mitigar la preocupación de la transferencia de material genético entre especies, medida por el hombre, ya que este tipo de fenómeno ocurre a diario en la naturaleza? (Muñoz, 2004, p. 266).

En lo que hace referencia a la variable del derecho al trabajo, se deduce que no existe vulneración, ya que se debería ponderar la vida del ser humano o un derecho del mismo, se trata de decir: de que sirve tener un derecho si pierdo la vida, si bien es cierto, los dos son derechos constitucionales, recordemos que, estos productos generan o producen un daño inminente en la salud, por ende al garantizar el uno se desprotege el otro, hay sin embargo quienes consideran que si se vulnera el derecho al trabajo, pues explican que no es responsabilidad de quien vende sino de quien consume. 


\section{PROPUESTA}

El Art. 401 de la Constitución de la Republica declara al Ecuador libre de cultivos y semillas transgénicas. Excepcionalmente, y sólo en caso de interés nacional debidamente fundamentado por la Presidencia de la República y aprobado por la Asamblea Nacional, se podrán introducir semillas y cultivos genéticamente modificados. El Estado regulará bajo estrictas normas de bioseguridad, el uso y el desarrollo de la biotecnología moderna y sus productos, así como su experimentación, uso y comercialización. Se prohíbe la aplicación de biotecnologías riesgosas o experimentales.

Para dar cumplimiento a lo que dice la norma, esta investigación ha centrado su proposición en la expedición de un protocolo de seguimiento y cumplimiento a todos los productores de organismos genéticamente modificados, sin excepción alguna, a fin de garantizar el derecho la salud de las personas.

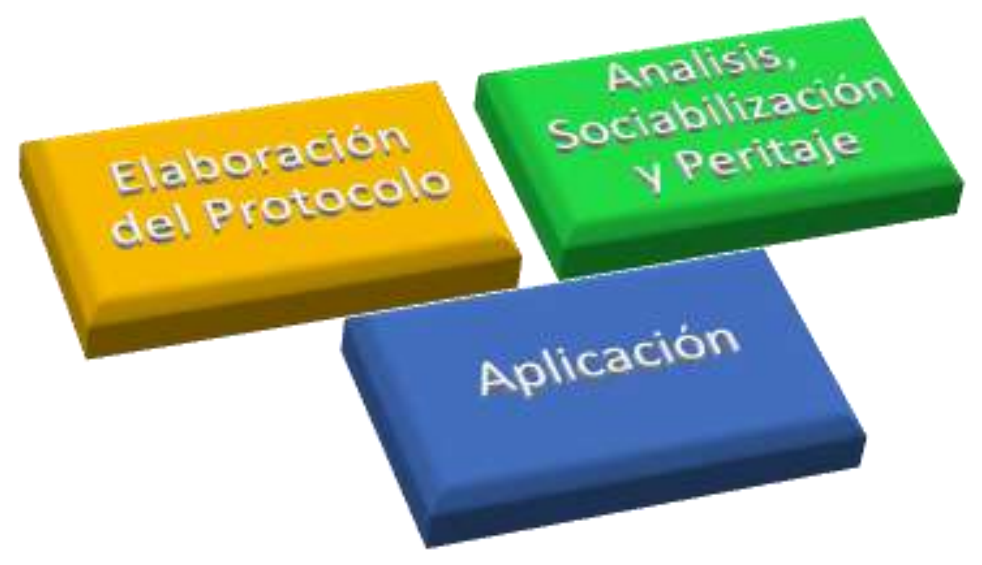

Figura 2. Estructura del proceso de la propuesta.

En consideración a estos antecedentes se recalca que:

a) El art. 13.- menciona que las personas y colectividades tienen derecho al acceso seguro y permanente a alimentos sanos, suficientes y nutritivos; preferentemente producidos a nivel local y en correspondencia con sus diversas identidades y tradiciones culturales. El Estado ecuatoriano promoverá la soberanía alimentaria. (Constitución de la República del Ecuador, 2008) 
b) El art. 15. Menciona que "se prohíbe...agentes biológicos experimentales nocivos y organismos genéticamente modificados perjudiciales para la salud humana o que atenten contra la soberanía alimentaria o los ecosistemas..." (Asamblea Constituyente, 2008).

Nuestra Constitución ecuatoriana recoge, por lo tanto, las condiciones del Buen Vivir dentro del artículo 275, el mismo que dice:

"Art. 275.- El régimen de desarrollo es el conjunto organizado, sostenible y dinámico de los sistemas económicos, políticos, socio-culturales y ambientales, que garantizan la realización del buen vivir, del sumak kawsay. El Estado planificará el desarrollo del país para garantizar el ejercicio de los derechos, la consecución de los objetivos del régimen de desarrollo y los principios consagrados en la Constitución. La planificación propiciará la equidad social y territorial, promoverá la concertación, y será participativa, descentralizada, desconcentrada y transparente. El buen vivir requerirá que las personas, comunidades, pueblos y nacionalidades gocen efectivamente de sus derechos, y ejerzan responsabilidades en el marco de la interculturalidad, del respeto a sus diversidades, y de la convivencia armónica con la naturaleza" (Asamblea Constituyente, 2008).

\section{PROTOCOLO DE SEGUIMIENTO, ANÁLISIS Y CUMPLIMIENTO DEL DERECHO} LA SALUD FRENTE A LOS ORGANISMOS MODIFICADOS GENÉTICAMENTE.

\section{Articulo 1.- Objeto}

El vigente protocolo, asume como particularidad el dar seguimiento y cumplimiento a los organismos modificados genéticamente en torno a sus productores.

\section{Artículo 2.- Ámbito de aplicación}

El vigente protocolo será aplicable a todos los productores de organismos modificados genéticamente dentro del territorio ecuatoriano, garantizando el derecho a la salud y el derecho al trabajo.

\section{Artículo 3.- Fases de trabajo:}

a) Formación.- Sociabilización a todos los productores de alimentos para que se relacionen con el objetivo y jerarquía de dar seguimiento a sus productos que se van 
a comercializar, mediante sociabilizaciones. Los resultados se verán reflejados en la edificación del protocolo.

b) Prueba Pericial.- Realizar un peritaje a todos los productos que pretendan transformar su estado natural a químico, con certificación previa a su distribución a fin de demostrar que no son nocivos para la salud, y no violentan las garantías constitucionales.

c) Acaparamiento.- El transporte y almacenamiento deberán cumplir con las normas de salubridad e higiene, para proteger el medio ambiente.

Artículo 4.- Resultados.- Su información serán rotulados para advertencia del consumidor.

Articulo 5.- Sanción.- El incumplimiento a lo dispuesto en este artículo, negará la producción, venta y distribución de los alimentos transgénicos, y será considerado infracción muy grave.

La finalidad total del protocolo es para respaldar nuestra Carta Magna y velar por las Políticas de Salud en relación a una vida saludable e integral, garantizando las condiciones del Buen Vivir.

\section{DISCUSIÓN}

Vinculado al concepto se centra su investigación en los organismos genéticamente modificados, demostrando de este modo que al pasar por un proceso de transformación, alteran su estado, de natural a químico, acelerando su crecimiento, perdiendo su esquema natural, causando posibles daños a la salud, violentando así el art. 13 de la Constitución de la República del Ecuador, con respecto al acceso seguro y permanente a alimentos sanos, suficientes y nutritivos, cabe considerar, por otra parte que el art. 15 del mismo cuerpo normativo, que indica: "se prohíbe....agentes biológicos experimentales nocivos y organismos genéticamente modificados perjudiciales para la salud humana o que atenten contra la soberanía alimentaria...", y al realizar transformaciones en sus genes estamos violentando lo antes indicado. Hay que recalcar que el art. 358 de nuestra Carta Magna vela por el sistema nacional de salud que tendrá por finalidad el desarrollo, protección y recuperación de las capacidades y potencialidades para una vida saludable e integral, en concordancia 
con el art. 275 que recoge las condiciones del Buen Vivir. Desde este punto de vista se determina que los organismos genéticamente modificados, han sido implantados de manera periódica en alimentos naturales, imponiendo así ejecuciones contra las políticas de la salud, para ejecutar diversas formas de transformación en los productos provocando así daños emergentes a los humanos.

La investigación ha ponderado varios derechos tutelados y amparados por la ley entre ellos el derecho a la salud y el derecho al trabajo, con el afán de resolver el problema del consumidor, siempre respetando las garantías del debido proceso que se encuentran consagradas en la Constitución, así como también en los instrumentos internacionales, no obstante para denotar que no se violen sus derechos.

A la actualidad es menester demostrar a plenitud las victimas por el uso de químicos en los alimentos, de allí, es que cabe la exigencia de plantear cambios en la transformación de sus genes o plantear determinantes previas a su producción, ya que las mismas no cumplen a la actualidad con los protocolos establecidos en las Políticas de la Salud, de tal manera que se deja a ciencia incierta sus falencias a los grandes empresarios.

Al respecto varios expertos en la rama de medicina consideran que los organismos genéticamente modificados no son nocivos para la salud, pero si discurren que sería necesario un previo análisis, a fin de proporcionar más fuentes de trabajo, en tal virtud los entendidos en Derecho, desisten de este criterio aludiendo que el mismo hecho de alterar un producto natural a químico vulneran los derechos constitucionales.

Haciendo énfasis en que no se vulnera el derecho al trabajo porque no se puede trabajar en lo que está prohíbo por la ley, a eso se suma el criterio personal de los abogados en libre ejercicio quienes exponen de manera equitativa a los productores, consumidores y a los trabajadores, indicando que para evitar dicho conflicto concuerdan con la labor realizar un protocolo que respalde a la Constitución con respecto al análisis de los químicos agregados a todo tipo de alimentos, considerando que deberían ser realizados por peritos expertos en la rama.

\section{FINANCIAMIENTO}

No monetario. 


\section{AGRADECIMIENTO}

A la Universidad Católica de Cuenca por motivar la realización de esta investigación.

\section{REFERENCIAS CONSULTADAS}

Abad Romero, G. E., Erazo Álvarez, J. C., Ormaza Ávila, D. A., \& Narváez Zurita, C. I. (2020). Proyecto de reforma a la Ley de Fomento Ambiental: Optimización de los Ingresos del Estado. Iustitia Socialis, 200.

Acción Ecológica. (2013). Análisis de la nueva matriz productiva para el agro [Analysis of the new productive matrix for agriculture]. Alerta Verde.

Almendrales, C., Cante, M., Riaño, Z., Moreno, J., \& Duarte, J. P. (2012). Promoción de la alimentación saludable y la actividad física en la organización curricular por ciclos educativos [ Promoting healthy eating and physical activity in curricular organization by educational cycles ]. Bogotá: Secretaría Distrital de Educación de Bogotá.

Asamblea Constituyente. (20 de Octubre de 2008). Constitución de la República del Ecuador [Constitution of the Republic of Ecuador] . Registro oficial No. 449. Monte Cristi, Manabi, Ecuador: Registro Oficial No. 449.

Asamblea Nacional. (20 de Octubre de 2008). Constitucion de la Republica del Ecuador [ Constitution of the Republic of Ecuador ]. R.0.449,20 de octubre. Quito, Pichincha, Ecuador: Editora Nacional. Recuperado el 16 de OCTUBRE de 2018, de Fiel Web (www.fielweb.com)

Bello, J. (2015). Calidad de vida, Alimentos y Salud Humana [ Quality of life, Food and Human Health]. Madrid: Diaz de Santos, S.A.

Bravo-Núñez, A. d., Narváez-Zurita, C. I., Vázquez-Calle, J. L., \& Erazo-Álvarez, J. C. (2020). Reparación integral de la Corte Interamericana de Derechos Humanos: Sentencias de acción extraordinaria de protección. Iustitia Socialis, 584-607. doi:http://dx.doi.org/10.35381/racji.v5i8.592

Calle, A. I., Narváez, C. I., \& Erazo, J. C. (2019). Auditoria en prevención de riesgos laborales y salud ocupacional: Procedimiento sistémico aplicado a la empresa Jasetrón. [ Audit in prevention of occupational risks and occupational health: Systemic procedure applied to the company Jasetrón]. Revista Arbitrada Interdisciplinaria Koinonía, 25-55. doi:http://dx.doi.org/10.35381/r.k.v4i2.466

Chumbi-Pulla, T. A., Erazo-Álvarez, J. C., Trelles-Vicuña, D. F., \& Narváez-Zurita, C. I. (2020). La reparación integral y su cuantificación en el daño inmaterial y proyecto de vida [Comprehensive reparation and its quantification in non- 
pecuniary damage and life project]. Iustitia Socialis, 527-546. doi:http://dx.doi.org/10.35381/racji.v5i8.589

Constitución de la República del Ecuador. (2008). Salud [ Bless you ]. Monte Cristi: Corporación de Estudios y Publicaciones.

Galperín, C., Fernández, L., \& Doporto, I. (2013). Los productos transgénicos, el comercio agrícola y el impacto sobre el agro argentino [GMO products, agricultural trade and the impact on Argentine agribusiness]. Documentos de Trabajo Área de Comercio Exterior. Buenos Aires, Buenos Aires, Argentina: Universidad de Belgrano.

Gómez, R. (2012). La agricultura orgánica: los beneficios de un sistema de producción sostenible [ Organic agriculture: the benefits of a sustainable production system ]. Tesis. Lima, Lima, Perú: Universidad del Pacífico.

ISAAA. (05 de Mayo de 2015). International Service for the Acquisition of Agri-biotech Applications . Obtenido de www.isaaa.org

La Vía Campesina. (05 de Mayo de 2015). La Vía Campesina: Movimiento Campesino Internacional [The Peasant Way: International Peasant Movement]. Obtenido de www.viacampesina.org

León, X. (2013). Transgénicos, agroindustria y soberanía alimentaria [ Transgenics, agribusiness and food sovereignty. ]. Letras Verdes-Revista Latinoamericana de Estudios Socioambientales, 29-53. doi:https://doi.org/10.17141/letrasverdes.16.2014.1235

Manrique, G., \& Verduzco, G. (2011). Uso de semillas geneticamente modificadas e incremento del ingreso de los agricultores [Use of genetically modified seeds and increased income of farmers].

Muñoz, J. (2004). Alimentos Transgénicos[ Transgenic Food]. Mexico: siglo xxi editores, s. a. de c. v.

Organización Mundial de la Salud. (Octubre de 2016). http://www.who.int. Recuperado el 17 de OCTUBRE de 2018, de http://www.who.int/governance/eb/who_constitution_sp.pdf

Ramírez, M. (2013). Los alimentos transgenicos, impacto de una realidad peligrosa y principio de una muerte lenta a largo plazo [ Transgenic foods, the impact of a dangerous reality and the beginning of a long-term slow death ]. Revista Enfermeria A la Vanguardia, 71.

Ramón, D. (2014). Avances en biotecnología de alimentos [ Advances in food biotechnology ]. Obtenido de Biotecnología Española: http://dx.doi.org/10.3989/arbor.2014.768n4005 
Rodríguez, E. (2005). Metodología de la Investigación [ Research Methodology ]. Mexico: Coleccion Hector Merino Rodriguez.

Rodríguez, E. (2013). Temas éticos en investigación internacional con alimentos transgénicos[Ethical topics in international research with GMO foods]. Acta bioethica, 209-218.

Romero, J. (2012). Derecho y alimentos transgénicos [ Law and GMO foods ]. Revista de Ciencias Jurídicas, 89-138.

Segrelles, J. (2013). El problema de los cultivos transgénicos en América Latina: una" nueva" revolución verde [ The problem of GMO crops in Latin America: a "new" green revolution ]. Entorno Geográfico.

Villafuerte, E., \& Figueroa, B. (2013). Soberanía Alimentaria y su Tipificación en el Código Penal Ecuatoriano. Vía Reforma Legal [ Food Sovereignty and its Typification in the Ecuadorian Penal Code. Via Legal Reform]. Tesis. Machala, El Oro, Ecuador: Universidad Tecnológica de Machala.

Waldmueller, J., \& Rodriguez, L. (2015). La Soberanía alimentaria más allá de la tecnica[ Food Sovereignty Beyond The Technique ]. Revista del Centro Andino de Estudios Internacionales. 